\title{
Kroppsstørrelse ved fødsel og brystkreftrisiko i voksen alder: En prospektiv befolkningsundersøkelse
}

\author{
Lars J. Vatten ${ }^{1}$, Tom I. Lund Nilsen ${ }^{1}$, Steinar Tretli ${ }^{1,2}$, Dimitrios Trichopoulos ${ }^{3}$ \\ og Pål R. Romundstad ${ }^{1,2}$ \\ (1) Institutt for samfunnsmedisin, Norges teknisk-naturvitenskapelige universitet, Trondheim \\ (2) Kreftregisteret, Oslo \\ (3) Department of Epidemiology, Harvard School of Public Health, Boston, MA, USA
}

Korrespondanse: Professor Lars Vatten, Institutt for samfunnsmedisin, Norges teknisk-naturvitenskapelige universitet, 7489 Trondheim Telefon: 73598787 Telefax: 73598789 E-post: lars.vatten@medisin.ntnu.no

\begin{abstract}
SAMMENDRAG
Bakgrunn: Utgangspunktet for studien er hypotesen om at kvinner som er født relativt store har økt risiko for å utvikle brystkreft som voksne.

Målsetting: Å undersøke om fødselslengde, fødselsvekt og hodeomkrets er av betydning for brystkreftrisiko i voksen alder.

Design: Kohort av kvinner med lang tids oppfølging gjennom Kreftregisteret.

Sted: St. Olavs Universitetssykehus i Trondheim.

Deltakere: 16016 kvinner født mellom 1920 og 1958 som var i live og kunne identifiseres gjennom folketellingen i 1960 .

Mål på effekt: Relativ risiko (RR) for brystkreft med 95\% konfidensintervall (KI).

Resultater: Det var en positiv sammenheng mellom fødselslengde og risiko for brystkreft, og sammenhengen var omtrent den samme før og etter 50-års alder. Den relative risiko for kvinner i den høyeste av fem lengdekategorier ( $\geq 53 \mathrm{~cm})$ var 1,8 (KI 1,2-2,5), sammenliknet med kvinner i den laveste $(<50 \mathrm{~cm})$, og justering for fødselsvekt påvirket ikke resultatet. I forhold til fødselsvekt var den relative risiko $1,4(\mathrm{KI} 1,0-2,0)$ for kvinner i den høyeste ( $\geq 3840$ gram) sammenliknet med den laveste (<3040 gram) kategorien, men gjensidig justering for fødselsvekt svekket assosiasjonen (RR 1,1). Kvinner i den høyeste kategori for både fødselslengde og vekt hadde mer enn dobbelt (RR 2,2, KI 1,3-3,6) så høy risiko for brystkreft som kvinner i den laveste kategori for begge faktorene. Justering for alder ved første fødsel, parietet og maternelle faktorer (alder, høyde, sosioøkonomiske faktorer) påvirket ingen av disse resultatene i noen vesentlig grad.

Konklusjon: Resultatene av denne undersøkelsen støtter hypotesen om at intrauterine faktorer har betydning for framtidig risiko for brystkreft. Den klare sammenhengen med fødselslengde tyder på at faktorer som stimulerer fosterets lengdevekst kan ha særlig betydning.
\end{abstract}

Nokkelord: Brystkreft, fødselsvekt, fødselslengde, hodeomkrets

Det ligger implisitt $\mathrm{i}$ hypotesen om at brystkreft kan ha sin opprinnelse in utero at faktorer som stimulerer intrauterin vekst også kan øke jenters risiko for brystkreft i voksen alder ${ }^{1}$. De fleste som har testet hypotesen har brukt fødselsvekt som indikator for fostervekst. Resultatene fra tre kohortstudier ${ }^{2-4}$, en "nested" case-control studie ${ }^{5}$ og elleve case-control studier $^{6-16}$ er ikke konklusive, men tyder på at fødselsstørrelsen og fosterveksten kan være av betydning for å utvikle brystkreft senere i livet.

Vi har undersøkt en relativt stor kohort av norske kvinner, og studert sammenhengen mellom størrelse ved fødsel og framtidig risiko for brystkreft. Vi har hatt tilgang på data som ble samlet inn i forbindelse med fødselen (fødselsvekt, fødselslengde, hodeomkrets, placentas vekt, svangerskapets varighet); opplysninger $\mathrm{i}$ voksen alder som er relevant for brystkreft (alder ved første fødsel og parietet); og lang tids oppfølging for å registrere nye tilfeller av brystkreft gjennom Kreftregisteret.

\section{METODER}

\section{Populasjonen}

Vi har registrert opplysninger fra fødejournaler for perioden 1920-1958 som er oppbevart ved St. Olavs Universitetssykehus i Trondheim. Journalførte opplysninger fra alle fødsler som fant sted ved daværende EC Dahls stiftelse, for i alt 21147 nyfødte jenter, er registrert. Vi ekskluderte 537 tvillinger, slik at populasjonen i utgangspunktet bestod av 20610 nyfødte. Regional komite for medisinsk forskningsetikk har vurdert og anbefalt studien gjennomført. 
Det sentrale personregister ved Statistisk Sentralbyrå vedlikeholder og oppdaterer informasjon om kvinners barnefødsler, hvor de bor, og inneholder blant annet mødrenes navn. I EC Dahls stiftelse var de nyfødte registrert på morens navn, og for mødre som var i live i 1960 og fikk fødselsnummer, var det derfor mulig å identifisere døtre som også var i live i 1960, og som var født på EC Dahls stiftelse i perioden 19201958. For mødre som var døde før de fikk fødselsnummer var det ikke alltid mulig å verifisere døtrenes identitet. I tillegg skiftet døtrene som regel navn når de giftet seg, og kombinasjonen mors død før 1960 og annet etternavn enn mor gjorde det vanskelig å være sikker på datterens identitet. Av i alt 20610 døtre var vi imidlertid sikre på identiteten til 16016, og disse kvinnene er fulgt opp med hensyn til brystkreft gjennom kobling til Kreftregisteret.

For kvinner født før 1941 ble oppfølgingstiden regnet fra 1. januar 1961. Oppfølgingstiden endte på tidspunktet for en av følgende begivenheter: hvis kvinnen fikk diagnostisert brystkreft eller annen kreft, dersom hun emigrerte ut av landet, eller hvis hun døde av annen årsak enn kreftsykdom. For de fleste inntraff ikke noen av disse begivenhetene, og for dem tok oppfølgingen slutt den 31. desember 2001. Blant dem som var født i 1941 eller senere begynte oppfølgingen når de fulgte 20 år. Brystkreft ble registrert i Kreftregisteret $\mathrm{i}$ henhold til den internasjonale klassifisering av sykdom (ICD, sjuende revisjon, kode 170).

Fra fødejournalene registrerte vi følgende opplysninger: fødselsvekt (gram), fødselslengde $(\mathrm{cm})$, hodeomkrets (cm), placentas vekt (gram) og svangerskapets varighet (angitt i uker eller måneder). Vi registrerte også tilgjengelig klinisk informasjon, spesielt opplysninger om maternell hypertensjon i svangerskapet og preeklampsi. Av andre maternelle opplysninger registrerte vi høyde og ekteskapelig status. Blant mødre som var gift da datteren ble født brukte vi mannens yrke som indikator på sosioøkonomisk status; dersom moren var ugift brukte vi hennes eget yrke. Informasjonen om mors eller fars arbeid var ikke systematisk registrert for alle, men vi brukte disse opplysningene $\mathrm{i}$ analyser av deler av befolkningen for å undersøke om det er sannsynlig at hovedfunnene i undersøkelsen kunne være konfundert av sosioøkonomiske forhold tidlig i livet.

For kvinner som var født i 1930 og senere hadde vi også informasjon om barnefødsler som var stilt til disposisjon fra Det Sentrale Personregister. For en del av kohorten kunne vi derfor bruke data om alder ved første fødsel og parietet, det vil si faktorer med en etablert assosiasjon til brystkreftrisiko.

\section{Statistiske metoder}

De kontinuerlige variablene (fødselsvekt, lengde, hodeomkrets og placentas vekt) ble kategorisert i tilnærmete kvintiler. Vi beregnet effekten av hver enkelt fødselsfaktor i forhold til risiko for brystkreft, uttrykt som insidens rate ratio (RR) ut fra Cox regresjonsanalyser, og justerte for kohort-effekter ved å kategorisere fødselsår (1920-1958) i 5-års intervaller. Ved å studere brystkreft separat for kvinner over og under 50 år kunne vi tilnærmet skille mellom effekter av fødselsfaktorene blant pre- og postmenopausale kvinner. Presisjonen av estimatene ble beregnet med 95\% konfidensintervaller (KI). I regresjonsanalysen justerte vi for potensiell konfundering, og inkluderte alder ved første fødsel, parietet, og de maternelle faktorene alder, høyde, ekteskapelig status og sosioøkonomiske forhold. Vi undersøkte også om forholdet mellom fødselsstørrelse og brystkreftrisiko var ulikt blant kvinner som hadde en relativt høy versus relativt lav mor, ved å bruke median høyde hos mor som skille mellom høy og lav.

\section{RESUltater}

Vi fulgte 16016 kvinner født mellom 1920 og 1958 med hensyn til insidens av brystkreft fram til slutten av 2001. I løpet av oppfølgingstiden fikk 312 kvinner diagnostisert sykdommen; 167 før fylte 50 år, og 145 ble diagnostisert blant kvinner 50 år og eldre. Den relativt store andelen unge pasienter avspeiler at kohorten som helhet fortsatt er relativt ung. Median alder ved diagnose var 49,1 år (range, 25-76 år). I oppfølgingsperioden (1961-2001) ble 798 kvinner diagnostisert med annen kreftsykdom, hvorpå de ble sensurert fra videre oppfølging. Dessuten døde 484 kvinner av andre årsaker enn kreft og ble sensurert, og 325 som emigrerte ble sensurert på tidspunkt for emigrasjon.

Våre resultater viser en moderat men positiv assosiasjon mellom fødselsvekt og risiko for brystkreft (Tabell 1). Sammenhengen var ikke konsistent over kategoriene for fødselsvekt ( $\mathrm{p}$ for trend, 0,17), men viste en moderat forøkt risiko knyttet til den høyeste kategorien. Kvinner som veide 3840 gram (høyeste kvintil) eller mer ved fødselen hadde en justert relativ risiko på 1.4 (KI 1,0-2,0) sammenliknet med kvinner som veide mindre enn 3040 gram (laveste kvintil), justert for svangerskapets varighet, maternelle faktorer og risikofaktorer i voksen alder. Dersom man samtidig justerte for fødselslengde ble denne assosiasjonen svekket (RR 1,1, KI 0,7-1,8).

Vi fant en signifikant positiv trend over kategoriene for fødselslengde ( $\mathrm{p}$ for trend, 0,02, Tabell 1), men relativ risiko-estimatene tyder på at økningen i risiko bare var til stede $\mathrm{i}$ den høyeste kategori av fødselslengde. Kvinner i høyeste $(\geq 53 \mathrm{~cm})$ kategori hadde en relativ risiko på 1,8 (KI 1,2-2.5) sammenliknet med den laveste $(<50 \mathrm{~cm})$ kategorien. Justering for faktorene ovenfor påvirket ikke resultatene i nevneverdig grad, og samtidig justering for fødselsvekt svekket heller ikke sammenhengen med fødselslengde.

For hodeomkrets fant vi tilsvarende sammenheng, med økt risiko knyttet til den høyeste kategorien av hodeomkrets (Tabell 1). Kvinner i høyeste kvintil ( $\geq 37$ $\mathrm{cm}$ ) ved fødsel hadde en relativ risiko på 1,5 (KI 1,0- 
2,2) sammenliknet med kvinner som hadde mindre hodeomkrets enn $34 \mathrm{~cm}$. Ved å sammenlikne kvinner som var i høyeste kvintil med dem som var i de fire nederste kvintilene til sammen, var den relative risiko assosiert med den høyeste kategori 1,7 (KI 1,2-2,3, data ikke vist).

Vi analyserte også om disse faktorene hadde ulik effekt for kvinner før og etter 50 års alderen. Hensikten var på en tilnærmet måte å skille mellom pre- og postmenopausale kvinner. Resultatene var imidlertid like i de to gruppene (data ikke vist).

Vi kombinerte også fødselslengde og vekt på en slik måte at vi sammenliknet kvinner som var i den høyeste kategori for begge variable med kvinner som var i den laveste både for fødselslengde og vekt. Resultatene viste at kvinner som var relativt store da de ble født (37 tilfeller blant 1565 kvinner) hadde omtrent dobbelt (RR 2,2, KI 1,3-3,6) så høy risiko for brystkreft som kvinner som var relativt små (42 tilfeller blant 2267 kvinner). Dette viser at den positive sammenhengen med brystkreftrisiko kan knyttes til den ekstreme kategorien av fødselsstørrelse, som vist på en konsistent måte både for fødselslengde, vekt og hodeomkrets (Tabell 1).

I tilleggsundersøkelser fant vi at assosiasjonen mellom fødselsvekt og brystkreftrisiko ble modifisert av mors høyde (Tabell 2). Sammenhengen med fødselslengde var mye sterkere dersom mor var relativt høy ( $p$ for trend, 0,001) enn dersom mor var relativt kort av vekst ( $\mathrm{p}$ for trend, 0,58). For fødselsvekt viste resultatene et liknende mønster, men estimatene var svakere enn for fødselslengde (Tabell 2).
Tabell 1. Relativ risiko for brystkreft assosiert med fødselsstørrelse.

\begin{tabular}{lrrcr}
\hline & Tilfeller & Kvinner & RR $(95 \% \mathrm{KI})^{\mathrm{a}}$ & $P$-trend \\
\hline Fødselsvekt $(\mathrm{g})$ & & & & \\
$<3040$ & 50 & 2964 & 1,0 & \\
$3040-3310$ & 74 & 3186 & $1,4(1,0-2,0)$ & \\
$3320-3550$ & 51 & 3278 & $1,0(0,7-1,5)$ & \\
$3560-3830$ & 67 & 3283 & $1,3(0,9-1,8)$ & \\
$\geq 3840$ & 69 & 3300 & $1,4(1,0-2,0)$ & 0,17 \\
& & & & \\
Fødselslengde (cm) & & & & \\
$<50$ & 87 & 4095 & 1,0 & \\
50 & 78 & 3764 & $1,0(0,7-1,4)$ & \\
51 & 55 & 3002 & $1,1(0,8-1,6)$ & \\
52 & 41 & 2794 & $1,0(0,7-1,5)$ & \\
$\geq 53$ & 51 & 2358 & $1,8(1,2-2,5)$ & 0,02 \\
& & & & \\
Hodeomkrets (cm) & & & & \\
$<34$ & 52 & 2660 & 1,0 & \\
34 & 72 & 3768 & $1,0(0,7-1,5)$ & \\
35 & 85 & 4520 & $1,0(0,7-1,4)$ & \\
36 & 57 & 3184 & $1,0(0,7-1,5)$ & \\
$\geq 37$ & 45 & 1820 & $1,5(1,0-2,2)$ & 0,11 \\
& & & & \\
Plasentavekt (g) & & & & \\
$<560$ & 35 & 2762 & 1,0 & \\
$560-620$ & 50 & 2885 & $1,3(0,9-2,0)$ & \\
$630-700$ & 57 & 3310 & $1,3(0,8-1,9)$ & \\
$710-780$ & 39 & 2769 & $1,0(0,7-1,7)$ & \\
$\geq 790$ & 50 & 2547 & $1,4(0,9-2,2)$ & 0,33 \\
\hline
\end{tabular}

${ }^{\mathrm{b} J u s t e r t ~ f o r ~ f ø d s e l s a ̊ r ~(1920-1924, ~ 1925-1929, ~ . . ., ~ 1955-1958) ~}$

${ }^{\mathrm{b}}$ Tosidige $P$-verdier for trend i Cox regresjon

Tabell 2. Relativ risiko for brystkreft assosiert med fødselsvekt og fødselslengde, stratifisert etter mors høyde (median).

\begin{tabular}{|c|c|c|c|c|c|c|c|c|}
\hline & \multicolumn{4}{|c|}{ Mors høyde $<163 \mathrm{~cm}$} & \multicolumn{4}{|c|}{ Mors høyde $\geq 163 \mathrm{~cm}$} \\
\hline & Tilfeller & Kvinner & $\mathrm{RR}(95 \% \mathrm{KI})^{\mathrm{a}}$ & $P$-trend ${ }^{\mathrm{b}}$ & Tilfeller & Kvinner & $\mathrm{RR}(95 \% \mathrm{KI})^{\mathrm{a}}$ & $P$-trend ${ }^{\mathrm{b}}$ \\
\hline \multicolumn{9}{|c|}{ Fødselsvekt (g) } \\
\hline$<3040$ & 22 & 1552 & 1,0 & & 12 & 1014 & 1,0 & \\
\hline $3040-3310$ & 41 & 1626 & $1,8(1,1-3,0)$ & & 22 & 1247 & $1,4(0,7-2,9)$ & \\
\hline $3320-3550$ & 25 & 1538 & $1,2(0,7-2,2)$ & & 17 & 1454 & $1,0(0,5-2,1)$ & \\
\hline $3560-3830$ & 24 & 1363 & $1,3(0,7-2,2)$ & & 30 & 1604 & $1,6(0,8-3,1)$ & \\
\hline$\geq 3840$ & 23 & 1264 & $1,4(0,8-2,5)$ & 0,76 & 39 & 1794 & $1,9(1,0-3,7)$ & 0,03 \\
\hline \multicolumn{9}{|c|}{ Fødselslengde (cm) } \\
\hline$<50$ & 44 & 2192 & 1,0 & & 18 & 1291 & 1,0 & \\
\hline 50 & 39 & 1838 & $1,1(0,7-1,6)$ & & 21 & 1482 & $1,0(0,5-1,9)$ & \\
\hline 51 & 22 & 1342 & $1,0(0,6-1,7)$ & & 25 & 1441 & $1,5(0,8-2,8)$ & \\
\hline 52 & 16 & 1154 & $0,9(0,5-1,7)$ & & 21 & 1462 & $1,3(0,7-2,5)$ & \\
\hline$\geq 53$ & 17 & 818 & $1,4(0,8-2,7)$ & 0,58 & 35 & 1436 & $2,5(1,4-4,6)$ & 0,001 \\
\hline
\end{tabular}

${ }^{\mathrm{a}}$ Justert for fødselsår (1920-1924, 1925-1929, .., 1955-1958)

${ }^{\mathrm{b}}$ Tosidige $P$-verdier for trend i Cox regresjon 


\section{DISKUSJON}

I denne kohortundersøkelsen fant vi en positiv sammenheng mellom kroppstørrelse og framtidig risiko for brystkreft. Resultatene var omtrent like for kvinner før og etter 50 års alder. Dermed er disse resultatene annerledes enn resultatene fra en nylig publisert kohortundersøkelse basert på svenske data. Den viste en klar positiv sammenheng mellom indikatorer på fostervekst og framtidig risiko for brystkreft blant premenopausale kvinner, men ingen sammenheng blant postmenopausale ${ }^{3}$. På den annen side viste en stor dansk kohortstudie en positiv sammenheng mellom fødselsvekt og brystkreftrisiko, både blant pre- og postmenopausale kvinner ${ }^{4}$, og disse resultatene sammenfaller med våre.

Vår studie hadde forskningsdesign tilsvarende den svenske $^{3}$ i og med at vi brukte opplysninger fra en kohort av kvinner født ved ett sykehus i kombinasjon med kobling til det nasjonale kreftregister i oppfølgingen av nye krefttilfeller. Begge undersøkelsene viste også at justering for risikofaktorer i voksen alder (for eksempel alder ved første fødsel, parietet, maternell høyde og fars yrke) ikke endret sammenhengen mellom fødselskarakteristika og brystkreftrisiko i voksen alder. Den svenske studien, basert på en oppfølging av 5358 kvinner født mellom 1915 og 1929, resulterte i 63 premenopausale og 295 postmenopausale kvinner med brystkreft. På den annen side bestod vår kohort av 16016 kvinner født mellom 1920 og 1958; 167 tilfeller med brystkreft ble diagnostisert før fylte 50 år, mens 145 brystkrefttilfeller ble diagnostisert senere. Begge undersøkelsene hadde tilnærmet fullstendig kreftoppfølging på grunn av det unike fødselsnummer i begge land. Det som skilte kohortene var at den norske var større og yngre, med nesten tre ganger så mange brystkrefttilfeller diagnostisert før 50 års alder sammenliknet med den svenske kohorten.

Tidlige studier som har undersøkt sammenhengen mellom fødselsstørrelse og brystkreftrisiko har kommet til ulike resultater ${ }^{2-16}$. Til å begynne med ble to andre svenske studier ${ }^{7,9}$ publisert som også brukte fødselsstørrelse registrert fra et befolkningsbasert fødselsarkiv, men disse anvendte et case-control design. Den første av de to studiene viste en positiv men svak sammenheng mellom fødselsvekt og brystkreftrisiko ${ }^{7}$, mens den andre 9 , som omfattet data fra fire fødselsenheter i tillegg til den forste, ikke kunne bekrefte resultatene av den første studien. I den prospektive Nurses' Health Study ${ }^{5}$ var det en positiv sammenheng mellom fødselsvekt og brystkreftrisiko som viste en linear trend over kategoriene for fødselsvekt. I den studien var det mødrene som opplyste om fødselsstørrelsen til sine døtre, enten på grunnlag av hukommelsen, eller på grunnlag av personlige dokumenter, begge potensielle feilkilder. I tillegg var en stor andel av mødrene ute av stand til å svare på forespørselen, og det resulterte $\mathrm{i}$ manglende data, og ingen mulighet for oppfølging av døtrene $\mathrm{i}$ forhold til dette spørsmålet. Det er en styrke ved vår undersøkelse at den brukte nøyaktige målinger av fødselslengde og vekt, samt muligheten for å justere for faktorer $\mathrm{i}$ voksen alder, slik som alder ved første fødsel og parietet, i tillegg til den fullstendige oppfølgingen $\mathrm{i}$ forhold til brystkreftinsidens $i$ en stor og uselektert befolkning.

Vi fant en positiv sammenheng mellom fødselslengde og brystkreftrisiko. Den nylige kohortstudien basert på svenske data fant en sterk positiv sammenheng mellom fødselslengde og risiko for premenopausal brystkreft, men ikke for postmenopausal sykdom ${ }^{3}$. I de fleste ${ }^{7,9,12}$, men ikke alle ${ }^{16}$ tidligere studier har den positive sammenhengen med fødselslengde vært svak og ikke statistisk signifikant. I vår undersøkelse er det verdt å merke seg at sammenhengen med fødselslengde forble uforandret etter justering for fødselsvekt, mens sammenhengen med fødselsvekt ble svekket etter justering for fødselslengde. Dette funnet kan styrke hypotesen om at longitudinell vekst svært tidlig i livet er av betydning for framtidig risiko for brystkreft.

Den sterke og konsistente sammenhengen mellom fødselslengde og brystkreftrisiko som vi fant i denne studien kan også knyttes til betydningen av høydevekst senere i livet, som vist gjennom den konsistente positive sammenhengen mellom høyde i voksen alder og risiko for brystkreft ${ }^{17}$. Den mindre konsistente sammenhengen med fødselsvekt kan tenkes å ha sammenheng med at fødselsvekt gir uttrykk for en kombinasjon av longitudinell vekst og vektøkning ${ }^{18}$. Kroppsmasseindeks i voksen alder viser ulik effekt på brystkreftrisiko, avhengig av en kvinnes menopausestatus ${ }^{17}$. Kanskje reflekteres dette forholdet i den mindre konsistente sammenhengen med brystkreft som vi fant for fødselsvekt enn for fødselslengde?

I separate analyser kombinerte vi opplysninger om fødselsvekt og lengde for å sammenlikne brystkreftrisikoen blant kvinner som var relativt store og relativt små ved fødsel ${ }^{19}$. Denne tilnærmingen styrket den positive sammenhengen mellom fødselsstørrelse og brystkreftrisiko, idet den store gruppen hadde mer enn dobbelt så høy risiko for brystkreft i voksen alder som den mindre gruppen. I tillegg undersøkte vi om mors høyde kunne modifisere sammenhengen med fødselsstørrelse ved å studere sammenhengen med brystkreft blant kvinner som hadde henholdsvis kortvokste og høye mødre. Resultatene viste at sammenhengen med fødselslengde var mye sterkere dersom mor var relativt høy. Tolkningen av dette funnet er ikke opplagt, men tyder på at en kombinasjon av genetisk vekstpotensial, indikert av mors høyde, og intrauterin vekst, som indikert av fødselslengde, kan tenkes å være en viktig determinant for framtidig brystkreft. En britisk kohortstudie har vist at den positive sammenhengen mellom fødselsstørrelse og brystkreftrisiko var begrenset til kvinner som var høye i 7-års alderen, noe som igjen kan tyde på at sammenhengen med intrauterin vekst kan modifiseres av kroppsveksten i barneårene ${ }^{2}$. 
Denne studien viser at intrauterine faktorer kan ha betydning for framtidig brystkreftrisiko. Den positive sammenhengen med fødselslengde tyder på at relevante underliggende faktorer kan stimulere fosterets lengdevekst.
St. Olavs fødselskohort er finansiert av støtte fra Kreftforeningen og Norges forskningsråd.

Studien er anbefalt av den regionale komite for medisinsk forskningsetikk, datakoblinger er godkjent av Datatilsynet og dispensasjon fra taushetsplikten er gitt av Sosial- og helsedirektoratet.

\section{REFERANSER}

1. Trichopoulos D. Does breast cancer originate in utero? Lancet 1990; 335: 939-940.

2. De Stavola BL, Hardy R, Kuh D, dos Santos Silva I, Wadsworth M, Swerdlow AJ. Birthweight, childhood growth and risk of breast cancer in a British cohort. Br J Cancer 2000; 83: 964-968.

3. McCormack VA, dos Santos Silva I, De Stavola BL, Mohsen R, Leon DA, Lithell HO. Fetal growth and subsequent risk of breast cancer: results from long term follow up of Swedish cohort. BMJ 2003; 326: 248-253.

4. Ahlgren M, Sørensen T, Wohlfahrt J, Haflidadóttir Á, Holst C, Melbye M. Birth weight and risk of breast cancer in a cohort of 106,504. Int J Cancer 2003; 107: 997-1000.

5. Michels K, Trichopoulos D, Robins JM, Rosner BA, Manson JE, Hunter DJ, et al. Birthweight as a risk factor for breast cancer. Lancet 1996; 348: 1542-1546.

6. Le Marchand L, Kolonel LN, Myers BC, Mi M-P. Birth characteristics of premenopausal women with breast cancer. Br J Cancer 1988; 57: 437-439.

7. Ekbom A, Trichopoulos D, Adami HO, Hsieh CC, Lan SJ. Evidence of prenatal influences on breast cancer. Lancet 1992; 340: 1015-1018.

8. Sanderson M, Williams MA, Malone KE, Stanford JL, Emanuel I, White E, et al. Perinatal factors and the risk of breast cancer. Epidemiology 1996; 7: 34-37.

9. Ekbom A, Hsieh CC, Lipworth L, Adami HO, Trichopoulos D. Intrauterine environment and breast cancer risk in women: a population-based study. J Natl Cancer Inst 1997; 89: 71-76.

10. Sanderson M, Williams MA, Malone KE, Stanford JL, Emanuel I, White E, et al. Perinatal factors and risk of breast cancer. Br J Cancer 1998; 57: 437-439.

11. Innes K, Byers T, Schymura M. Birth characteristics and subsequent risk for breast cancer in very young women. Am J Epidemiol 2000; 152: 1121-1128.

12. Hübinette A, Lichtenstein P, Ekbom A, Cnattingius S. Birth characteristics and breast cancer risk: a study among like-sexed twins. Int J Cancer 2001; 91: 248-251.

13. Kaijser M, Lichtenstein P, Granath F, Erlandsson G, Cnattingius S, Ekbom A. In utero exposures and breast cancer: a study of opposite-sexed twins. J Natl Cancer Inst 2001; 93: 60-62.

14. Titus-Ernstoff L, Egan KM, Newcomb PA, Ding J, Trentham-Dieta A, Greenberg ER, et al. Early life factors in relation to breast cancer risk in postmenopausal women. Cancer Epidemiol Biomarkers Prev 2002; 11: 207-210.

15. Sanderson M, Shu XO, Jin F, Dai Q, Ruan Z, Gao Y-T, et al. Weight at birth and adolescence and premenopausal breast cancer risk in a low-risk population. Br J Cancer 2002; 86: 84-88.

16. Vatten LJ, Maehle BO, Lund Nilsen TI, Tretli S, Hsieh C-C, Trichopoulos D, et al. Birth weight as predictor of breast cancer: a case-control study in Norway. Br J Cancer 2002; 86: 89-91.

17. van den Brandt PA, Spiegelman D, Yaun SS, Adami HO, Beeson L, et al. Pooled analysis of prospective cohort studies on height, weight, and breast cancer risk. Am J Epidemiol 2000; 152: 514-527.

18. Trichopoulos D. Intrauterine environment, mammary gland mass and breast cancer risk. Breast Cancer Res 2003; 5: 42-44.

19. Marshall JR. The use of dual or multiple reports in epidemiology. Stat Med 1989; 9: 1041-1049. 